\title{
Determinan Kematian Neonatal Pada Bayi Berat Lahir Rendah di Indonesia (Analisis Data SDKI 2002-2003 dan 2007)
}

\author{
Izza Suraya \\ Program Studi Kesehatan Masyarakat, Fakultas Ilmu-Ilmu Kesehatan \\ Universitas Muhammadiyah Prof. Dr. HAMKA \\ email: izza_suraya@uhamka.ac.id
}

\author{
ABSTRACT \\ Determination of Neonatal Death in Low Birth Weight Infants in Indonesia \\ (Data Analysis of IDHS 2002-2003 and 2007)
}

\begin{abstract}
Introduction. There were $72.4 \%$ infants with less than 2.500 grams Low Birth Weight (LBW) babies died in their neonatal period in Indonesia. An understanding of all factors that influenced the neonatal death is important. Therefore, this study was conducted to identify factors of $L B W$ neonatal death between 1997 and 2007.

Methods. Based on 2002-2003 and 2007 Indonesia Demographic Health Survey, 1,232 LBW babies are selected. The design of study was cohort prospectif with cox proportional hazard analysis to measure the relationship between neonatal death and its determinants maternal, infant, health care, and mother's social demographic.

Resuls. After controlling all the variables, the result showed that neonatal death in LBW babies deteriminants are immediate breastfeeding, birth weight, sex, the term of birth, complications during pregnancy, delivery complications, birth attendance, type of delivery, place of delivery, wealth index, and mother's education. Variable that showed strongest risk association is complications during pregnancy with $H R=4.12(95 \% C I: 0.64-26,65 ; p$ value $=0.307)$. Meanwhile, the strongest of protective association is middle class on wealth index variable.

Conclusions. The study concluded that birth weight influences the incidence of neonatal death. Determinant that have the greatest effect on neonatal death is complications during pregnacy. Infants who born from middle-class economic categories are the most protective factor to avoid neonatal deaths among other wealth indexes.
\end{abstract}

Keywords: Low Birth Weight (LBW), IDHS 2002-2003 and 2007, determinants

\section{PENDAHULUAN}

Kematian neonatal merupakan kematian pada periode saat bayi lahir hidup hingga bayi berumur 28 hari (WHO, 2006). Kematian neonatal tersebut dibagi kedalam dua fase, yakni kematian early neonatal dan kematian late neonatal. Dalam satu dekade terakhir, penurunan kematian neonatal mengalami penurunan hanya sebesar 7\%. (Yinger dan Ransom, 2003). Bahkan, Persatu Bangsa Bangsa (PBB) memperkirakan bahwa dua pertiga dari kematian bayi saat ini merupakan kematian neonatal. Dengan kata lain, sejumlah empat juta bayi neonatal mengalami kematian di seluruh dunia (30 per 1000 bayi lahir hidup). Kematian neonatal tersebut, banyak terjadi pada bayi dengan berat lahir rendah (BBLR) (Child Health Research Project Special Report, 1999; WHO SEARO, 2006; Golestan dkk,
2008; Ribeiro dkk, 2009; Yasmin dkk, 2001; Mufti dkk, 2006). Sementara di Indonesia, berdasarkan Survei Demografi dan Kesehatan Indonesia (SDKI) 2002, 72,4\% bayi dengan berat kurang dari 2.500 gram mengalami kematian saat neonatal (Titaley dkk, 2008).

Semakin rendah berat lahir bayi, semakin besar probabilitas kematian neonatalnya (Wilcox, 2001; Trotman dan Lord, 2007). Seiring dengan hal tersebut, risiko kematiannya juga lebih tinggi (Onis, 2001; Tommiska, 2001). Odds yang lebih besar dalam hubungan tersebut didapatkan dalam penelitian Titaley di Indonesia, sebesar 6,27 (Titaley dkk, 2008). Selain berat lahir, kematian neonatal juga dipengaruhi oleh faktor bayi seperti jenis kelamin (Lawn dkk, 2005). Beberapa studi menyatakan bahwa laki-laki memiliki risiko lebih tinggi untuk meninggal 
pada masa neonatal dibandingkan dengan bayi perempuan (Titaley dkk, 2008; Itabashi dkk, 2009). Dari segi maternal, BBLR yang memiliki ibu dengan paritas dua atau lebih mempunyai risiko besar untuk mengalami kematian nenonatal (Child Health Research Project Special Report, 1999; Forssas dkk, 1999).

Kematian BBLR saat neonatal juga dipengaruhi oleh faktor pelayanan kesehatan. Sebuah penelitian menyatakan kelahiran di luar rumah sakit memiliki risiko untuk mengalami kematian neonatal (Titaley dkk, 2008; Ballot dkk, 2010). Studi lain di Ghana mengungkapkan bahwa BBLR yang tidak disusui dalam kurun waktu satu jam setelah lahir memiliki risiko sebesar 2,61 kali untuk mengalami kematian pada masa neonatal dibandingkan dengan ibu yang melakukannya (Edmond dkk, 2007). Di samping itu, kondisi sosial ekonomi ibu dan keluarga bayi juga mempengaruhi kematian neonatal BBLR. Bayi dengan ibu yang memiliki latar pendidikan Sekolah Menengah Pertama (SMP) memiliki angka kematian neonatal yang lebih besar dibandingkan dengan ibu dengan pendidikan lebih tinggi (Golestan dkk, 2008 dan Diallo dkk, 2011). Melihat besarnya masalah kematian neonatal di Indonesia, maka studi ini dilakukan untuk mengetahui determinan yang mempengaruhi kematian neonatal tersebut.

\section{METODE}

Studi ini menggunakan data sekunder yang berasal dari SDKI 2002-2003 (26 provinsi) dan SDKI 2007 (33 provinsi). Oleh karena itu, populasi studi ini adalah seluruh provinsi di Indonesia yang ada pada sumber data sekunder tersebut. Sedangkan sampel diambil melalui dua tahap (two stages sampling). Pada tahap pertama, dilakukan pemilihan sampel 3.286 blok sensus (SDKI 2002-2003 sebanyak 1.592 blok sensus dan SDKI 2007 sebanyak 1.694 blok sensus). Pemilihan tersebut dilakukan dengan menggunakan cara PPS (Probability Proportional to Size). Pada tahap kedua, sebanyak 25 rumah tangga dipilih secara sistematik dari masing-masing blok sensus terpilih. Dengan demikian, sejumlah 77.079 rumah tangga terpilih (SDKI 2002-2003 sebanyak 34.738 dan SDKI 2007 sebanyak 42.341 rumah tangga).

Pengumpulan data pada rumah tangga terpilih dilakukan melalui wawancara tatap muka. Dari seluruh 73.789 rumah tangga yang berhasil di wawancarai, terdapat 31.593 wanita usia 15-49 tahun yang pernah mengandung bayi lahir pada tahun 1998-2007 (SDKI 2002-2003 sebanyak 15.089 wanita dan SDKI 2007 sebanyak 16.504 wanita). Seluruh wanita tersebut memiliki jumlah bayi sebesar 34.851 orang. Untuk mendapatkan populasi sumber, yaitu bayi dengan berat lahir $<2.500$ gram (BBLR), seluruh data bayi tersebut disaring kembali dan didapatlah 1.858 BBLR (SDKI 2002-2003 sebanyak 832 bayi dan SDKI 2007 sebanyak 1026 bayi).

Dari populasi sumber tersebut, responden terpilih berdasarkan kriteria inklusi, yaitu kelahiran tunggal dengan berat minimal 1.500 gram sehingga terpilih 1.537 BBLR. Kemudian, karena tidak memiliki data pada beberapa variabel, sebanyak 258 BBLR yang bukan kelahiran terakhir juga dikeluarkan dari studi sehingga sampel yang eligible sebesar 1.279 sampel. Untuk menyamakan peluang terpilih pada setiap strata, sampel dibobot. Dengan demikian sampel yang masuk ke dalam analisis berjumlah 1.232 BBLR.

Adapun tujuan studi ini adalah ingin melihat faktor-faktor yang mempengaruhi kematian neonatal BBLR. Faktor-faktor yang dimaksud adalah faktor bayi/janin (jenis kelamin, preterm, dan pemberian ASI); faktor maternal (umur ibu, riwayat abortus pada ibu, komplikasi selama kehamilan, komplikasi persalinan, paritas, dan jarak kelahiran); faktor pelayanan kesehatan (antenatal care/ANC, penolong persalinan, tempat bersalin, jenis persalinan, dan kunjungan postnatal care/PNC); serta faktor sosial demografi ibu (tingkat kesejahteraan keluarga, tempat tinggal, dan pendidikan ibu).

Untuk melihat karakteritik dari seluruh responden, tabulasi frekuensi digunakan. 
Di samping itu, untuk mengukur hubungan antara variabel independen dengan dependen dilakukan uji statistik cox proportional hazard. Di dalam analisis multivariat, strategi pemodelan bertingkat digunakan untuk mendapatkan determinan yang berpengaruh terhadap kematian neonatal.

\section{HASIL}

Subjek yang ikut dalam studi ini sejumlah 1.232 BBLR, 587 bayi laki-laki $(47,66 \%)$ dan 645 bayi perempuan $(52,34 \%)$. Sejumlah $2,65 \%$ BBLR mengalami kematian pada masa neonatalnya. Sebagian besar $(46,23 \%)$ BBLR tersebut lahir dengan berat 2.000-2.200 gram. Berdasarkan usia kandungan, sebesar 54,65\% dilahirkan cukup bulan, $6,16 \%$ dilahirkan kurang bulan, 39,19\% lainnya tidak diketahui statusnya. Selain itu, berdasarkan waktu disusui dini, hanya $32 \%$ BBLR yang disusui dalam waktu kurang dari satu jam (Tabel 1).

Tabel 1 memperlihatkan faktor maternal dari responden. Sebanyak 75,84\% ibu BBLR berumur 20-35 tahun. Di samping itu, sebagian besar ibu tidak mempunyai riwayat aborsi $(88,2 \%)$, tidak mempunyai komplikasi kehamilan (82,37\%), dan juga tidak mempunyai komplikasi saat persalinan. Berdasarkan jumlah paritas, ibu yang telah melakukan persalinan satu kali hampir sama dengan ibu yang telah melahirkan 2-3 kali, yaitu masing-masing $41,48 \%$ dan $43,06 \%$. Sementara itu, sebesar $50,84 \%$ ibu mempunyai jarak persalinan lebih dari dua tahun.

Tabel 1 Distribusi Frekuensi BBLR di Indonesia Berdasarkan Faktor Maternal Pada Tahun 1998-2007

\begin{tabular}{|c|c|c|}
\hline Variabel & Frekuensi (n) & Presentase $(\%)$ \\
\hline \multicolumn{3}{|l|}{ Kematian Neonatal } \\
\hline Tidak & 1199 & 97,35 \\
\hline Ya & 33 & 2,65 \\
\hline \multicolumn{3}{|l|}{ Berat Lahir } \\
\hline 2201-2499 gram & 419 & 34,03 \\
\hline 2000-2200 gram & 570 & 46,23 \\
\hline 1500-1999 gram & 243 & 19,74 \\
\hline \multicolumn{3}{|l|}{ Jenis Kelamin } \\
\hline Laki-laki & 587 & 47,66 \\
\hline Perempuan & 645 & 52,34 \\
\hline \multicolumn{3}{|l|}{ Preterm } \\
\hline Tidak & 673 & 54,65 \\
\hline Ya & 76 & 6,16 \\
\hline Tidak Diketahui & 483 & 39,19 \\
\hline \multicolumn{3}{|l|}{ Inisiasi Disusui Dini } \\
\hline$<1 \mathrm{jam}$ & 395 & 32 \\
\hline $1-23$ jam & 256 & 21 \\
\hline$\geq 24$ jam & 472 & 38 \\
\hline Tidak Diketahui & 109 & 9 \\
\hline \multicolumn{3}{|l|}{ Umur Ibu } \\
\hline 15-19 tahun & 52 & 4,21 \\
\hline $20-35$ tahun & 934 & 75,84 \\
\hline$>35$ tahun & 246 & 19,96 \\
\hline \multicolumn{3}{|l|}{ Riwayat Aborsi } \\
\hline Tidak & 1087 & 88,2 \\
\hline $\mathrm{Ya}$ & 145 & 11,8 \\
\hline \multicolumn{3}{|l|}{ Komplikasi Kehamilan } \\
\hline Tidak ada komplikasi & 1015 & 82,37 \\
\hline Terdapat komplikasi & 217 & 17,63 \\
\hline \multicolumn{3}{|l|}{ Komplikasi Persalinan } \\
\hline Tidak ada komplikasi & 632 & 51,31 \\
\hline Terdapat komplikasi & 600 & 48,69 \\
\hline \multicolumn{3}{|l|}{ Paritas } \\
\hline 1 kali & 511 & 41,48 \\
\hline 2-3 kali & 530 & 43,06 \\
\hline$\geq 4$ kali & 191 & 15,47 \\
\hline \multicolumn{3}{|l|}{ Jarak Kelahiran } \\
\hline$>2$ tahun & 626 & 50,84 \\
\hline$\leq 2$ tahun & 95 & 7,68 \\
\hline Tidak Diketahui & 511 & 41,48 \\
\hline
\end{tabular}


Hasil studi juga menggambarkan BBLR berdasarkan pelayanan kesehatan yang diterimanya selama dalam kandungan, saat kelahiran, dan setelahnya. Tabel 2 menunjukkan, hampir seluruh BBLR memiliki telah mendapatkan pelayanan antenatal sesuai standar (96,44\%). Sebanyak 876 dari 1.232 BBLR memeriksa ANC tersebut ke tenaga kesehatan profesional. Selain itu, lebih dari setengah $(53,61 \%)$ BBLR dilahirkan di pelayanan kesehatan dan sebesar 58,99\% kelahiran BBLR ditolong oleh tenaga kesehatan profesional. Tabel 2 juga menunjukkan bahwa 90,13\% BBLR dilahirkan dengan cara non caesaria sectio. Setelah persalinan, setengah dari jumlah BBLR $(57,66 \%)$ tidak mendapatkan ASI selama tiga hari pertama. Berdasarkan variabel pelayanan setelah kelahiran (PNC), hasil studi menunjukkan bahwa 72,33\% BBLR melakukan kunjungan PNC pertama kali dalam kurun waktu 0-2 hari.

Tabel 2 Distribusi Frekuensi BBLR di Indonesia Berdasarkan Pelayanan Kesehatan yang Diterima Selama dalam Kandungan pada Tahun 1998 -2007

\begin{tabular}{|c|c|c|}
\hline \multicolumn{3}{|l|}{ Kunjungan ANC } \\
\hline Sesuai Standar & 1188 & 96,44 \\
\hline Tidak sesuai standar & 37 & 3,03 \\
\hline Tidak diperiksa & 7 & 0,55 \\
\hline \multicolumn{3}{|l|}{ Pemeriksa ANC } \\
\hline Tenaga Kesehatan & 876 & 71,12 \\
\hline Non Tenaga Kesehatan & 356 & 28,88 \\
\hline \multicolumn{3}{|l|}{ Penolong Persalinan } \\
\hline Tenaga Kesehatan & 727 & 58,99 \\
\hline Non Tenaga Kesehatan & 505 & 41,01 \\
\hline \multicolumn{3}{|l|}{ Tempat Persalinan } \\
\hline Pelayanan Kesehatan & 660 & 53,61 \\
\hline Non Pelayanan Kesehatan & 572 & 46,39 \\
\hline \multicolumn{3}{|l|}{ Jenis Persalinan } \\
\hline Non- Caesaria Section & 1110 & 90,13 \\
\hline Caesaria Section & 117 & 9,52 \\
\hline Tidak Diketahui & 5 & 0,36 \\
\hline \multicolumn{3}{|l|}{ ASI Eksklusif } \\
\hline Ya & 475 & 38,55 \\
\hline Tidak & 710 & 57,66 \\
\hline Tidak Diketahui & 47 & 3,8 \\
\hline \multicolumn{3}{|l|}{ Kunjungan Post Natal Care } \\
\hline 0-2 hari & 891 & 72,33 \\
\hline 3-6 hari & 79 & 6,38 \\
\hline 7-41 hari & 131 & 10,65 \\
\hline Tidak Diketahui & 131 & 10,63 \\
\hline
\end{tabular}

Tabel 3 menunjukkan distribusi frekuensi BBLR berdasarkan karakter sosial demografi ibu. Secara keseluruhan, mayoritas BBLR yang ikut dalam studi memiliki ibu yang digolongkan sebagai tingkat kesejahteraan "kaya" $(23,27 \%)$; bertempat tinggal di daerah rural $(57,77 \%)$; dengan ibu yang tidak bekerja $(57,15 \%)$; dan berpendidikan sekolah dasar $(50,27 \%)$. 
Tabel 3 Distribusi Frekuensi BBLR di Indonesia

Berdasarkan Karakter Sosial Demografi Ibu Tahun 1998 -2007

\begin{tabular}{lcc}
\hline \multicolumn{1}{c}{ Variabel } & Frekuensi (n) & Persentase (\%) \\
\hline Sangat Miskin & 251 & 20,34 \\
Miskin & 263 & 21,35 \\
Menengah & 209 & 16,97 \\
Kaya & 287 & 23,27 \\
Sangat Kaya & 222 & 18,06 \\
\hline Tempat Tinggal & & \\
Urban & 520 & 42,23 \\
Rural & 712 & 57,77 \\
\hline Ibu bekerja & & \\
Tidak & 704 & 57,15 \\
Ya & 526 & 42,7 \\
Tidak Diketahui & 2 & 0,15 \\
\hline Pendidikan Ibu & & \\
Tidak Berpendidikan & 38 & 3,07 \\
Sekolah dasar & 619 & 50,27 \\
\hline SLTP & 485 & 39,33 \\
SLTA & 90 & 7,33 \\
\hline
\end{tabular}

Saat mengukur hubungan bivariat dan multivariat, hanya 1.174 sampel yang dapat dianalisis karena hanya mereka yang mempunyai data lengkap. Setelah dilakukan evaluasi interaksi dan confounder, determinan yang mempunyai pengaruh terhadap kematian neonatal adalah berat lahir, jenis kelamin, komplikasi persalinan, penolong persalinan, jenis persalinan, pemberian ASI eksklusif selama tiga hari setelah kelahiran, tingkat kesejahteran, dan pendidikan ibu. Melihat secara substansi preterm dan komplikasi kehamilan memiliki andil dalam ketahanan hidup BBLR, maka kedua variabel tersebut dinilai terlibat dalam kematian neonatal BBLR.

Salah satu determinan yang mempunyai pengaruh terhadap kejadian kematian neonatal adalah berat lahir (tabel 4).
Bayi di dalam kelompok berat lahir sebesar 2.000-2.200 gram mempunyai risiko 2,71 lebih besar untuk mengalami kematian neonatal dibandingkan bayi yang mempunyai berat lahir 2.201-2.499 gram. Namun, untuk bayi di kelompok 1.500-1.999 gram, risiko tersebut lebih kecil, yaitu 1,47. Dari segi umur kelahirannya, bayi yang lahir belum cukup bulan mempunyai risiko sebesar 3,92 kali untuk mengalami kematian neonatal. Determinan yang membawa pengaruh paling besar adalah komplikasi selama persalinan dengan risiko 4,12 . Selain itu, bayi dengan ibu yang memiliki pendidikan tinggi (minimal SLTP) memiliki risiko sebesar 1,52 kali untuk mengalami kematian neonatal dibandingkan dengan bayi dengan ibu berpendidikan dasar (tabel 4).

Tabel 4 Faktor-Faktor Yang Mempengaruhi Kematian Neonatal di Indonesia (1)

\begin{tabular}{|c|c|c|c|c|c|c|}
\hline \multirow{2}{*}{ Variabel } & \multicolumn{3}{|c|}{ Crude } & \multicolumn{3}{|c|}{ Adjusted } \\
\hline & $H R$ & $95 \% \mathrm{CI}$ & p value & $H R$ & $95 \% \mathrm{CI}$ & p value \\
\hline \multicolumn{7}{|l|}{ Berat Lahir } \\
\hline 2.201-.2499 gram & 1 & & & 1 & & \\
\hline $2.000-2.200$ gram & 1,98 & $0,54-7,26$ & 0,32 & 2,71 & $0,63-11,71$ & 0,181 \\
\hline $1.500-1.999$ gram & 2,51 & $0,73-8,60$ & 0,14 & 1,47 & $0,20-10,62$ & 0,699 \\
\hline \multicolumn{7}{|l|}{ Jenis Kelamin } \\
\hline Laki-laki & 1 & & & 1 & & \\
\hline Perempuan & 1,49 & $0,61-3,63$ & 0,38 & 1,5 & $0,51-4,45$ & 0,46 \\
\hline \multicolumn{7}{|l|}{ Preterm } \\
\hline Tidak & 1 & & & 1 & & \\
\hline Ya & 5,22 & $1,43-19,06$ & 0,01 & 3,92 & $0,79-19,61$ & 0,096 \\
\hline \multicolumn{7}{|l|}{ Komplikasi Kehamilan } \\
\hline Tidak ada komplikasi & 1 & & & 1 & & \\
\hline Terdapat komplikasi & 3,82 & $1,45-10,06$ & 0,01 & 4,12 & $0,64-26,65$ & 0,136 \\
\hline \multicolumn{7}{|l|}{ Komplikasi Persalinan } \\
\hline Tidak ada komplikasi & 1 & $1,33-8,42$ & 0,01 & 1 & $0,19-1,70$ & 0,307 \\
\hline Terdapat komplikasi & 3,34 & & & 0,57 & & \\
\hline \multicolumn{7}{|l|}{ Pendidikan Ibu } \\
\hline Pendidikan Dasar & 1 & & & 1 & 1 & \\
\hline Pendidikan Tinggi & 1,83 & $0,67-5,02$ & & 1,52 & $0,33-6,95$ & 0,592 \\
\hline
\end{tabular}


Di sisi lain, bayi yang lahir tanpa bantuan tenaga kesehatan memiliki odds sebesar 0,43 untuk terhindar dari kematian neonatal. (tabel 5). Tabel 5 juga memperlihatkan hubungan protektif yang lain. Hubungan protektif tersebut ditunjukkan oleh bayi yang lahir di non pelayanan kesehatan seperti rumah dan perjalanan, dengan nilai Hazard Ratio (HR) sebesar 0,22 . Jenis persalinan caesarian section juga membawa hubungan positif terhadap kematian neonatal. Dengan dilahirkan lewat proses caesar, bayi terlindungi dari kematian neonatal. Berdasarkan hasil studi terlihat bahwa bayi dengan kategori ekonomi keluarga kelas menengah mempunyai hubungan protektif yang paling dominan di antara wealth index lain yang signifikan untuk terhindar dari kematian neonatal. (tabel 5).

Tabel 5 Faktor-Faktor yang Mempengaruhi Kematian Neonatal di Indonesia (2)

\begin{tabular}{|c|c|c|c|c|c|c|}
\hline \multirow{2}{*}{ Variabel } & \multicolumn{3}{|c|}{ Crude } & \multicolumn{3}{|c|}{ Adjusted } \\
\hline & HR & $95 \% \mathrm{CI}$ & p value & HR & $95 \% \mathrm{CI}$ & p value \\
\hline \multicolumn{7}{|l|}{ Penolong Persalinan } \\
\hline Tenaga Kesehatan & 1 & & & 1,00 & & \\
\hline Non Tenaga Kesehatan & 0,91 & $0,32-2,56$ & 0,86 & 0,43 & $0,15-1,26$ & 0,146 \\
\hline \multicolumn{7}{|l|}{ Jenis Persalinan } \\
\hline Non- Caesaria Section & 1 & & & 1 & & \\
\hline Caesaria Section & 1,46 & $0,56-3,86$ & 0,44 & 0,22 & $0,033-5,022$ & 0,214 \\
\hline \multicolumn{7}{|l|}{ ASI Eksklusif } \\
\hline Ya & 1 & & & 1,00 & & \\
\hline Tidak & 2,98 & $0,72-12,19$ & 0,13 & 1,18 & $0,43-3,27$ & 0,74 \\
\hline Tidak Diketahui & 22,68 & $5,88-87,42$ & 0 & & & \\
\hline \multicolumn{7}{|l|}{ Tingkat Keseiahteraan } \\
\hline Sangat Miskin & 1 & & & 1 & 1 & \\
\hline Miskin & 1,05 & $0,25-4,25$ & 0,94 & 0,018 & $0,0007-0,47$ & 0,016 \\
\hline Menengah & 0,96 & $0,27-3,37$ & 0,95 & 0,001 & $\begin{array}{c}2,56 \mathrm{e}-17- \\
3,84 \mathrm{e}-16\end{array}$ & 0,001 \\
\hline Kaya & 1,22 & $0,31-4,85$ & 0,77 & 0,26 & $0,005-11,67$ & 0,489 \\
\hline Sangat Kaya & 2,38 & $0,70-8,02$ & 0,16 & 0,61 & $0,03-12,12$ & 0,747 \\
\hline
\end{tabular}

\section{PEMBAHASAN}

Kematian neonatal lebih banyak terjadi pada kelompok bayi dengan berat lahir rendah. Kematian tersebut dapat disebabkan oleh peralihan dari kehidupan intrauteri BBLR ke kehidupan ekstrauteri yang mengakibatkan banyak perubahan biokimia dan fisiologi. Saat di uterus, BBLR tidak mendapat dukungan plasenta yang adekuat sehingga tidak terdapat asupan glukosa dari ibu, persediaan karbohidrat menurun, dan oksigenasi terbatas. Dengan kondisi tersebut, saat dilahirkan, BBLR (terutama IUGR) tidak dapat mentoleransi dengan baik kekurangan aliran darah plasenta dan oksigen sehingga menyebabkan deselerasi denyut jantung dan berakhir pada kematian (Klaus dan Fanaroff, 1998).

Walaupun beragam studi menunjukkan bahwa risiko kematian neonatal semakin besar seiring dengan semakin rendah berat lahir bayi (Yasmin 2001), namun hasil studi ini menunjukkan hal yang sebaliknya. Kelompok berat lahir sebesar 2000-2200 gram mempunyai risiko 2,71 lebih besar untuk kematian neonatal dibandingkan bayi yang mempunyai berat lahir 2201- 2499 gram, sementara bayi di kelompok
1500-1999 gram mempunyai risiko sebesar 1,47. Hal ini dimungkinkan karena kelompok bayi dengan berat 1500-1999 gram mendapatkan perawatan yang lebih intensif di pelayanan kesehatan sehingga kesehatannya lebih terjamin.

Di samping itu, determinan yang membawa pengaruh paling besar adalah komplikasi selama persalinan dengan risiko 4,12. Komplikasi kehamilan merupakan penyulit atau penyakit yang menyertai proses kehamilan seperti preeklampsia, hiperemesis gravidarum, dan pendarahan. Komplikasi tersebut mengakibatkan pertumbuhan dan perkembangan janin di dalam kandungan terhambat sehingga mengakibatkan bayi meninggal pada masa neonatalnya.

Dari segi umur kelahirannya, bayi yang lahir belum cukup bulan (kurang dari 37 minggu) mempunyai risiko sebesar 3,92 kali untuk terkena kematian neonatal. Hal ini sejalan dengan studi yang menyatakan bahwa kelangsungan hidup bayi preterm lebih kecil dibandingkan dengan bayi fulltrem (Trotman dkk, 2007; Yasmin dkk, 2001; Ballot dkk, 2010). Besar risiko tersebut disebabkan karena 
fungsi organ tubuh bayi preterm belum sempurna sehingga sulit untuknya bertahan hidup. Selain itu, hasil studi ini juga meperlihatkan bahwa bayi dengan ibu yang memiliki pendidikan tinggi (minimal SLTP) memiliki risiko sebesar 1,52 kali untuk mengalami kematian neonatal dibandingkan dengan bayi yang berasal dari ibu berpendidikan dasar. Hal ini tidak sejalan dengan studi lain (Golestan, 2008).

Dilihat dari segi pelayanan kesehatan, hasil studi mengungkapkan bahwa bayi yang lahir tanpa bantuan tenaga kesehatan memiliki risiko sebesar 0,43. Artinya, bayi tersebut memiliki peluang 2,3 kali untuk terhindar dari kematian neonatal. Hal ini kemungkinan disebabkan bayi yang ditolong oleh tenaga kesehatan merupakan bayi rujukan yang mempunyai angka kegawatan tinggi sehingga peluang untuk diselamatkan lebih kecil. Selain itu, berdasarkan laporan SDKI 2002 - 2003 dan 2007, sebagian besar responden melakukan persalinan di bidan desa yang tidak memiliki kompetensi untuk menolong bayi dengan berat lahir yang rendah. Hubungan protektif juga ditunjukkan oleh bayi yang lahir di non pelayanan kesehatan seperti rumah dan perjalanan, dengan hazard ratio sebesar 0,22. Hal ini dapat disebabkan karena sebagian besar responden merupakan penduduk desa yang mempunyai akses terbatas pada pelayanan kesehatan sehingga memilih untuk melakukan persalinan di rumah.

Selain itu, jenis persalinan caesaria sectio juga menunjukkan efek perlindungan terhadap kematian neonatal. Dengan dilahirkan lewat proses caesar, bayi terlindungi dari kematian neonatal. Hal yang sama juga diungkapkan pada penelitian di Jamaika dan Ballot di Johanesberg (Trotman, 2007; Ballot, 2010). Menurut penelitian tersebut, bayi yang terlahir dengan jalan caesaria sectio lebih mampu bertahan daripada kelahiran pervaginal karena kelahirannya lebih terkontrol oleh tenaga kesehatan. Hasil studi juga memperlihatkan bahwa bayi dengan kategori ekonomi keluarga kelas menengah mempunyai hubungan protektif yang paling dominan di antara wealth indeks lain yang signifikan untuk terhindar dari kematian neonatal. Hal ini bertentangan dengan pernyataan dari penelitian lain (Lawn dkk, 2005).
Studi ini memiliki keterbatasan, yaitu diduga masih dipengaruhi bias informasi yang terjadi pada pengumpulan data terkait berat lahir. Walaupun terdapat kategori berat lahir dari Kartu Menuju Sehat (KMS) di dalam kuesioner, database SDKI yang diperoleh peneliti tidak dapat memperlihatkan hal tersebut. Informasi berat lahir yang digunakan dalam studi ini diduga hanya berdasarkan ingatan ibu saja. Dengan demkian, kesalahan dalam mengingat (recall bias) mungkin terjadi saat ibu menjawab pertanyaan tersebut. Jika kelahiran BBLR tersebut terjadi beberapa tahun lalu akan memperburuk kesalahan tersebut. Kesalahan serupa (recall bias) juga terjadi pada beberapa pertanyaan yang terkait dengan informasi di masa lampau seperti komplikasi kehamilan. Selain itu, hasil studi menunjukkan rentang confidence interval yang lebar pada nilai hazard. Hal ini mungkin disebabkan oleh kurangnya sampel dalam studi ini. Beberapa studi yang hampir serupa menggunakan sampel jauh lebih besar daripada besar sampel yang digunakan dalam studi ini.

Di balik keterbatasan tersebut, studi ini memiliki beberapa kekuatan. Salah satu kekuatan dalam studi ini adalah pengontrolan confounding dengan teknik restriksi pada kelahiran tunggal dan berat lahir 1500-2499 gram. Dengan demikian, efek menyimpang dari kedua faktor tersebut telah dieliminasi. Di samping itu, studi ini merupakan studi yang berbasis pada data survei dengan metode multistage sampling, maka analisis yang digunakan telah menggunakan teknik analisis data survei sehingga mendekati hasil yang sesungguhnya. Jika dilihat dari spesifisitas, studi ini mempunyai spesifisitas pada berat lahir yang dikelompokkan ke dalam beberapa kategori (1.500-1999 gram, 2.000-2.200 gram, dan 2.201-2.499 gram).

\section{KESIMPULAN}

Studi ini menyimpulkan bahwa berat lahir mempengaruhi kejadian kematian neonatal. Determinan yang membawa pengaruh paling besar pada kematian neonatal adalah komplikasi selama persalinan. Bayi yang lahir dari kategori ekonomi kelas menengah merupakan faktor paling protektif untuk terhindar dari kematian neonatal di antara wealth index lainnya. 


\begin{abstract}
ABSTRAK
Pendahuluan. Terdapat $72,4 \%$ bayi dengan berat $<2.500$ gram meninggal pada masa neonatal. Memahami faktor-faktor yang mempengaruhi kematian neonatal adalah penting. Studi ini dilakukan untuk mengukur hubungan faktor tersebut dengan kematian neonatal pada BBLR di Indonesia.

Metode. Studi ini menggunakan data SDKI 2002 - 2003 dan 2007 dengan jumlah sampel 1.232 BBLR. Desain yang digunakan adalah kohort retrospektif dengan Cox proportional hazard digunakan untuk mengetahui hubungan antara determinan kematian neonatal, yang terkait dengan faktor ibu, faktor bayi, pelayanan kesehatan dan sosial demografi ibu. Jumlah sampel yang masuk ke dalam analisis berjumlah 1.232 BBLR.

Hasil:. Setelah dikontrol, hasil studi menunjukkan bahwa kematian BBLR diduga dipengaruhi oleh waktu disusui pertama, berat lahir, jenis kelamin, preterm, komplikasi kehamilan, komplikasi persalinan, penolong persalinan, jenis persalinan, tempat persalinan, tingkat kesejahteraan, dan pendidikan ibu. Variabel yang mempunyai hubungan risiko paling kuat adalah komplikasi kehamilan dengan Hazard Ratio (HR) sebesar 4,12 (95\% CI : 0,64-26,65; p value =0,307). Sementara itu, hubungan paling kuat ditujukkan oleh tingkat kesejahteraan kelas menengah dengan $\mathrm{HR}=0,001(95 \%$ CI : 2,56e-17-3,84e-16; $p$ value $=0,001)$.

Kesimpulan. Studi ini menyimpulkan bahwa berat lahir mempengaruhi kejadian kematian neonatal. Determinan yang membawa pengaruh paling besar pada kematian neonatal adalah komplikasi selama persalinan. Bayi yang lahir dari kategori ekonomi kelas menengah merupakan faktor paling protektif untuk terhindar dari kematian neonatal di antara wealth index lainnya.
\end{abstract}

Kata Kunci: BBLR, Neonatal, SDKI 2002-2003 dan 2007, determinan

\section{DAFTAR PUSTAKA}

1. Ballot, D.E, Tobias F Chirwa, dan Peter A Cooper. (2010). Determinants Of Survival In Very Low Birth Weight Neonates In A Public Sector Hospital In Johannesburg. MC Pediatrics 30 (2010): 1471-2431.

2. Child Health Research Project Special Report. (1999). Reducing Perinatal and Neonatal Mortality. Baltimore: John Hopkins University, 1999

3. Diallo, AH, dkk. (2001). A Prospective Study On Neonatal Mortality And Its Predictors In A Rural Area In Burkina Fas : Can MDG-4 be met by 2015?. Journal Of Perinatology 31 (2011): 656-665.

4. Edmond, K.M., dkk. (2007). Effect Of Early Infant Feeding Practices On Infection-Specific Neonatal Mortality: An Investigation Of The Causal Links With Observational Data From Rural Ghana. The American Journal of Clinical Nutrition 86 ( 2007) :1126 -31.

5. Forssas, Erja, dkk. (1999). Maternal Predictors of Perinatal Mortality: The Role Of Birthweight. International Journal Of Epidemiology 28 (1999) : 475-478.

6. Golestan, Motahhareh, Razieh Fallah, dan Sedighah Karbasi. (2008). Neonatal Mortality Of Low Birth Weight Infants in Yazd, Iran. Iranian Journal of Reproductive Medicine 6 (2008) : 205-208.

7. Itabashi, Kazuo, dkk. (2009). Mortality Rates For Extremely Low Birth Weight Infants Born In Japan In 2005. Pediatrics 123 (2009) : 445450 .
8. Klaus, Marshall H., dan Avroy A. Fanaroff. (1998). Care of The High-Risk Neonate. Ed.ke4. Terj. Achmad Surjono. Jakarta : EGC, 1998.

9. Lawn JE, dkk. (2005). 4 Million Neonatal Deaths: When? Where? Why?. Lancet 2005, 365(2005):891-900.

10. Onis. (2001). Mercedes de. Intrauterine Growth Retardation. Health and Reemerging Issues in Developing Countries. WHO : 2001.

11. Ribeiro, Adolfo Monteiro, dkk. (2009). Risk Factors For Neonatal Mortality Among Children With Low Birth Weight. Rev Saude Publica 43 (2009).

12. Titaley, C.R., dkk. (2008). Determinants of Neonatal Mortality in Indonesia. BioMed Central 8 (2008):232

13. Tommiska, Viena, dkk. (2001). A National Short-Term Follow-Up Study of Extremely Low Birth Weight Infants Born in Finland in 19961997. Pediatrics 107 (2001) : 1-9.

14. Trotman, H, dan C Lord. (2007). Outcome of Extremely Low Birthweight Infants at the University Hospital of the West Indies, Jamaica. West Indian Med J 56 (2007): 409413.

15. Wilcox, Allen J. (2001). On The Importanceand The Unimportance-Of Birthweight. International Journal Of Epidemiology 30 (2001): 1233-1241.

16. World Health Organization. (2006). Neonatal and Perinatal Mortality : Country, Regional, and Global Estimates. Geneva, WHO : 2006. 
17. World Health Organization-Regional Office for South East. (2006). Operationalizing The Neonatal Health Care Strategy In South-East Asia Region. 11th Meeting of Health Secretaries of Member States of SEAR SEARO, New Delhi, 12-13 June 2006.
18. Yinger, N. V., dan Ransom, E. (2003). Why Invest in Newborn Health?. Policy Perspectives on Newborn Health, 1-6.

19. Yasmin S, dkk. (2001). Neonatal Mortality of Lowbirth Weight Infants In Bangladesh. Bulletin of the World Health Organization 7 (2001) : 608-614. 